11

\title{
Объемное микроструктурирование силикатного стекла фемтосекундным лазерным излучением
}

\author{
() А.Е. Рупасов ${ }^{1}$, П.А. Данилов ${ }^{1}$, М.П. Смаев ${ }^{1,2}$, М.С. Ковалёв ${ }^{3}$, А.С. Золотько ${ }^{1}$, А.А. Ионин ${ }^{1}$, \\ С.И. Кудряшов ${ }^{1,4}$ \\ ${ }^{1}$ Физический институт им. П.Н. Лебедева, \\ 119991 Москва, Россия \\ ${ }^{2}$ Российский химико-технологический университет им. Д.И. Менделеева, \\ 125047 Москва, Россия \\ ${ }^{3}$ Московский государственный технический университет им. Н.Э. Баумана, \\ 105005 Москва, Россия \\ ${ }^{4}$ Университет ИТМО, \\ 197101 Санкт-Петербург, Россия \\ e-mail: jkljnb16@gmail.com, m.s.kovalev@gmail.com
}

Поступила в редакцию 10.01.2020 г.

В окончательной редакции 11.02.2020 г.

Принята к публикации 28.02.2020 г.

Микроструктурирование силикатного стекла выполнялось путем линейного одномерного сканирования в объеме материала, сильно сфокусированного фемтосекундного лазерного пучка видимого диапазона c различной поляризацией. Оптическая микроскопия выявила при линейной и круговой поляризациях формирование микроструктур, демонстрирующих усиленную экстинкцию в синей области спектра, однако двулучепреломления в микроструктурах не было обнаружено.

Ключевые слова: прямая лазерная запись, фемтосекундные лазерные импульсы, объемные функциональные нано- и микрооптические метаструктуры, двулучепреломление.

DOI: $10.21883 / \mathrm{OS} .2020 .07 .49564 .48-20$

\section{Введение}

Прямая фемтосекундная запись в объеме диэлектриков позволяет создавать локальные постоянные модификации, которые могут находить свое применение в различных областях, например, для создания оптических волноводов, разветвителей, резонаторов в объеме активных сред, устройств микро- и нанофлюидики. Изменяя параметры излучения, можно получать различные типы модификаций или дефектов [1,2]. Выделяют следующие типы записанных фемтосекундными импульсами структур: области с отличным от исходного материала показателем преломления, двулучепреломляющие структуры, полости ит.д. Отдельно стоит отметить активно развивающиеся лазерную запись и долговременное хранение информации [3]. Методика основывается на создании объемной полости, структура и оптические свойства которой зависят от параметров излучения, при которых выполнялась обработка.

При взаимодействии ультракоротких лазерных импульсов с объемом стекла могут образовываться периодические нанорешетки [4]. Данные структуры представляют собой параллельные полосообразные области, направление которых зависит от поляризации лазерного пучка. Период самоорганизующихся нанорешеток зависит от энергии в импульсе и количества импульсов на точку, периодичность полос варьируется в пределах сотен нанометров, что меньше, чем длина волны записывающего лазера [5]. Свойства данных структур могут быть использованы для изготовления полуволновых и четвертьволновых пластинок, конверторов поляризации, поляризационно-зависимых устройств, а также замедлителей.

К другому виду структур, обладающих двулучепреломлением, следует отнести микроструктуры на основе микролиний в кристаллах сапфира [6], в этом случае двулучепреломление формировалось вследствие механических напряжений внутри области, не подвергавшейся лазерной обработке. Двулучепреломляющая структура в сапфире действует как одноосный отрицательный кристалл. Такие структуры можно использовать в качестве замедлителей, сдвиг по фазе составляет порядка $\lambda / 4$. Наибольший интерес представляет тот факт, что двулучепреломляющая область находится за пределами обрабатываемого участка, это, в свою очередь, позволяет избежать рассеяния света на дефектах, образованных при лазерном воздействии.

По сравнению с предшествующими исследованиями в настоящей работе изучается возможность создания структур, которые могут обладать двулучепреломлением в объеме силикатного предметного стекла, при прямой фемтосекундной лазерной записи массивов микролиний с учетом возможных проявлений, самоорганизованных нанорешеток и остаточных микромасштабных напряжений. Отличительной особенностью исследуемого ма- 

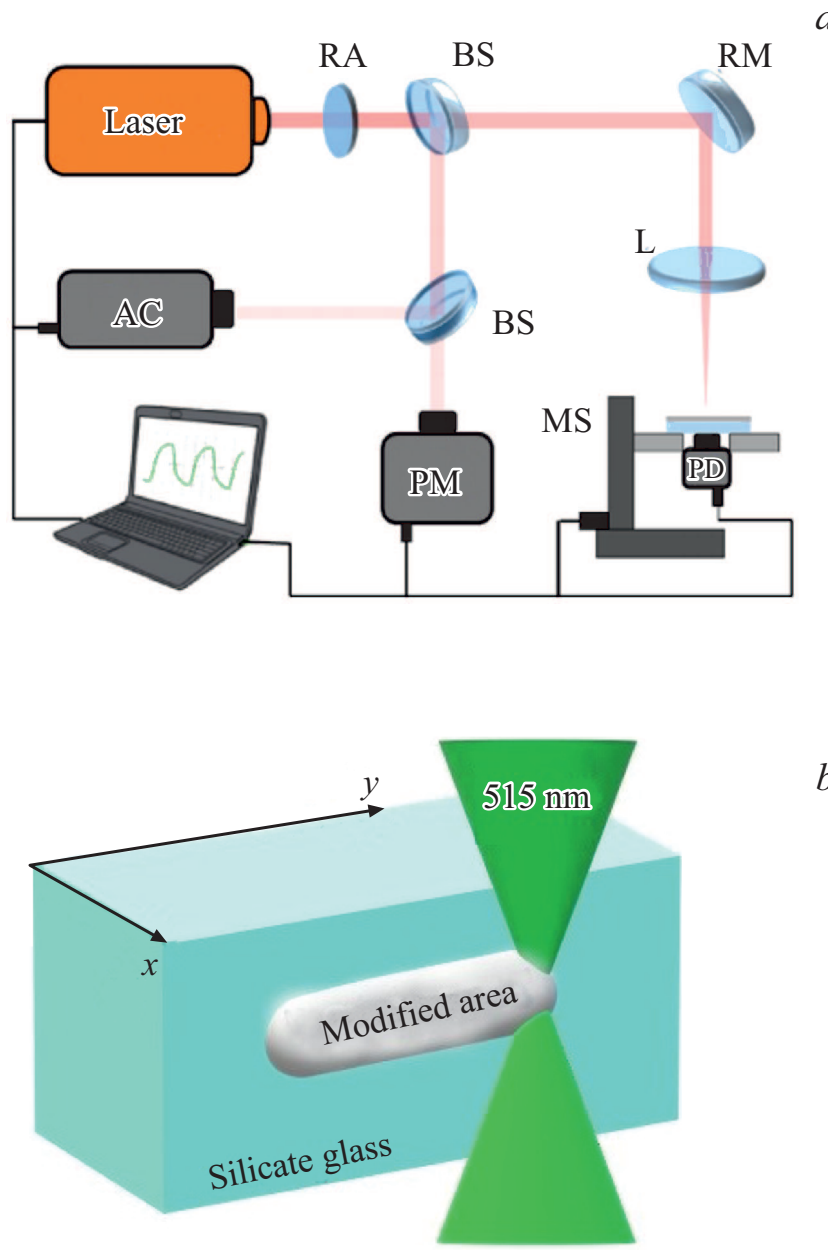

Рис. 1. Схематическая иллюстрация экспериментальной установки (a): Laser - лазерная система Satsuma (515 nm), RA отражающий аттенюатор, BS - светоделительная пластина, $\mathrm{RM}$ - отражающее зеркало, L - микрообъектив с числовой апертурой $N A=0.25, \mathrm{AC}-$ автокоррелятор, РМ измеритель мощности, PD - фотодиод, MS - трехосевая моторизованная платформа; схема модификации стекла $(b)$.

териала является присутствие значительного количества оптических неоднородностей и химических примесей.

\section{Экспериментальная часть}

В качестве источника фемтосекундных импульсов использовалась лазерная система Satsuma на основе волоконного иттербиевого лазера, состоящая из генератора со стретчером и многопроходного усилителя с диодным лазером накачки на длине волны $850 \mathrm{~nm}$, а также выходного компрессора и акустооптического модулятора, управляемых внешним компьютером (рис. 1). Система излучала серию импульсов с длительностью $300 \mathrm{fs}$ (ширина на полувысоте) и частотой повторения $250 \mathrm{kHz}$.
Результаты локального элементного анализа обрабатываемого стекла

\begin{tabular}{c|c|c}
\hline Элемент & Весовой, \% & Атомный, \% \\
\hline $\mathrm{O}$ & 42 & 56 \\
$\mathrm{Na}$ & 2 & 2 \\
$\mathrm{Mg}$ & 4 & 3 \\
$\mathrm{Si}$ & 52 & 39
\end{tabular}

Запись микроструктур производилась импульсным излучением с длиной волны $515 \mathrm{~nm}$ (вторая гармоника), энергия импульса составляла 160 nJ. Сканирование выполнялось по оси $Y$ (рис. $1, b$ ). Исходный лазерный пучок был линейно поляризован вдоль оси $X$, затем вектор поляризации изменялся с помощью полуволновых пластинок $\lambda / 2, \lambda / 4$ и их комбинаций. Для фокусировки использовался микрообъектив с числовой апертурой $\mathrm{NA}=0.25$. Лазерное излучение через делительное зеркало с пропусканием 50\% фокусировалось на поверхность образца в воздухе через объектив микроскопа в пятно радиусом $R_{1 / e}=2.2 \pm 0.1 \mu \mathrm{m}$. В ходе экспериментов в объеме стекла (на глубине $375 \mu \mathrm{m}$ ) были записаны структуры размером $625 \times 625 \mu \mathrm{m}$.

В качестве образцов использовались стандартные предметные стекла толщиной $1 \mathrm{~mm}$ на основе силикатного стекла. Элементный анализ материала выполнялся методом энерго-дисперсионной спектрометрии (EDS) с помощью спектрометра INCA Energy 350XT при энергии электронов $5 \mathrm{keV}$. Результаты приведены в таблице.

Для спектральных исследований коэффициента пропускания подготовленных микроструктур был использован микроскоп-спектрофотометр ЛОМО МСФУ-К. Использовался микрообъектив с числовой апертурой $\mathrm{NA}=0.25$, сфокусированный на глубину $375 \mu \mathrm{m}$. Размер области, спектр которой измерялся, определялся шириной щели $0.12 \mathrm{~mm}$ и размером диафрагмы $0.5 \mathrm{~mm}$. В качестве источника света применялась галогеновая лампа.

Исследование двулучепреломления в области, модифицированной фемтосекундным излучением, проводилось на оптическом микроскопе Olympus BX-61, оснащенном системой микроанализа двулучепреломления Abrio IM 2.2 (Cambridge Researce-, \& Instrumentation, Inc). Принцип функционирования Abrio описан в работе [9] и основан на использовании традиционной поляризационной микроскопии, возможности которой расширены использованием жидкокристаллического компенсатора фазы и специально разработанного алгоритма обработки сигнала. Исследуемый образец помещается на предметном столике микроскопа между циркулярным поляризатором и перестраиваемым жидкокристаллическим поляризатором (компенсатором фазы). Освещение, создаваемое лампой микроскопа и прошедшее через систему вышеописанных элементов, направлялось 


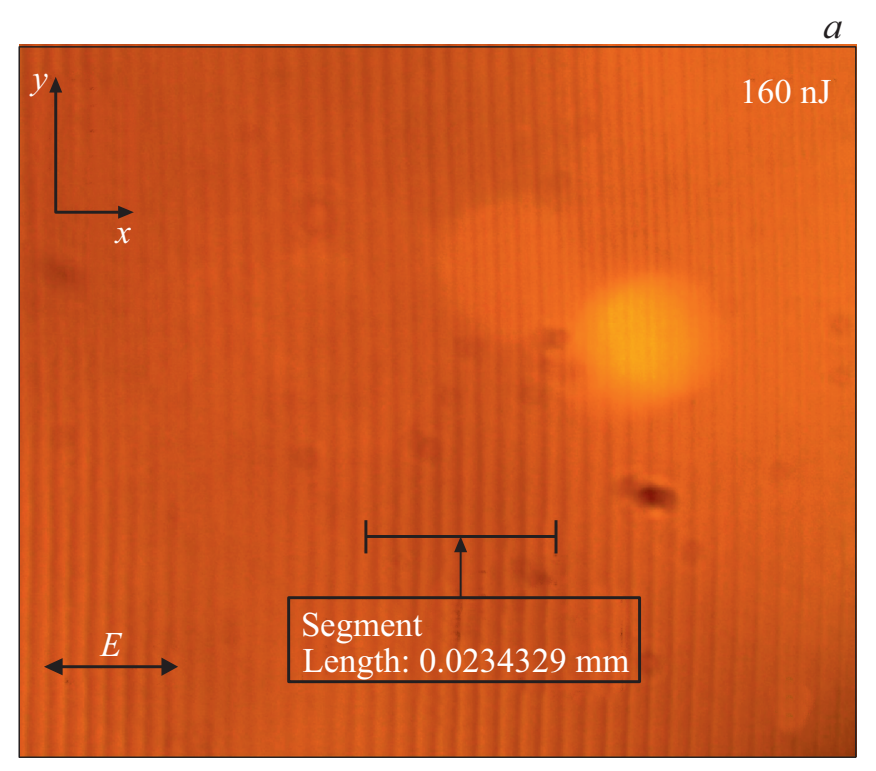

$b$

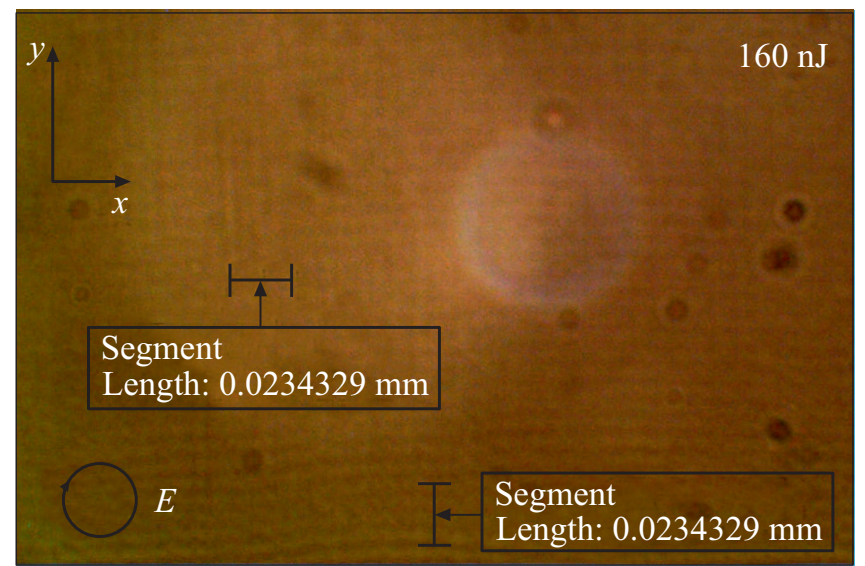

Рис. 2. Микроснимки областей объемной модификации силикатного стекла размером $625 \times 625 \mu \mathrm{m}$ в скрещенных поляризаторах А и С после записи пучком света, поляризованного линейно по оси $X(a)$ и по кругу $(b)$. Сканирование световым пучком выполнялось вдоль оси $Y$. Скорость записи $25 \mu \mathrm{m} / \mathrm{s}$.

на CCD камеру. Система микроанализа измеряет параметры поляризации светового поля в зависимости от пропускания жидкокристаллического компенсатора, управляемого встроенным контроллером, одновременно во всех точках образца внутри изучаемой области с высокими временным и пространственным разрешениями. В результате создается карта исследуемой области образца, причем яркость каждого пиксела пропорциональна локальной оптической анизотропии образца, но независима от ориентации образца в плоскости наблюдения. Величина двулучепреломления (retardance, Ret) характеризуется сдвигом между двумя ортогональными волновыми фронтами, прошедшими анизотропную структуру, выражена в долях длины волны и равна

$$
\text { Ret }=\Delta n \times L,
$$

где $\Delta n=\left|n_{e}-n_{o}\right|, \quad n_{e}-$ показатель преломления необыкновенной волны, $n_{o}$ - показатель преломления обыкновенной волны, $L$ - размер двулучепреломляющего объекта вдоль направления наблюдения (оптической оси микроскопа). Кроме того, на созданной карте анизотропии система Abrio отображает ориентацию медленной оси двулучепреломляющего объекта (показывает направление оси с максимальным показателем преломления).

\section{Результаты и их обсуждение}

Для массивов микролиний, записанных лазерным пучком с линейной поляризацией, микромасштабная визуализация структуры неполяризованным белым светом в скрещенных поляризаторах, при различных положениях поляризатора, показывает наличие рассеяния света по направлению записи линий (рис. 2,a). Напротив, для массивов микролиний, записанных светом с круговой поляризацией, микромасштабная визуализация структуры в скрещенных поляризаторах показывает рассеяние света в перпендикулярно-параллельных направлениях (рис. 2,b). При этом снимки без скрещенных поляризаторов различаются незначительно, разница состоит лишь в интенсивности подсветки.

Влияние поляризации фемтосекундного лазерного излучения существенно сказывается на спектрах пропускания модифицированных областей (рис. 3). В целом модификация приводит к появлению наведенного поглощения в синей области спектра. С другой стороны, спектр массива линий, записанного излучением с круговой поляризацией, показывает меньшую модуляцию по сравнению со спектрами массивов, записанных при линейной поляризации излучения, ориентированной

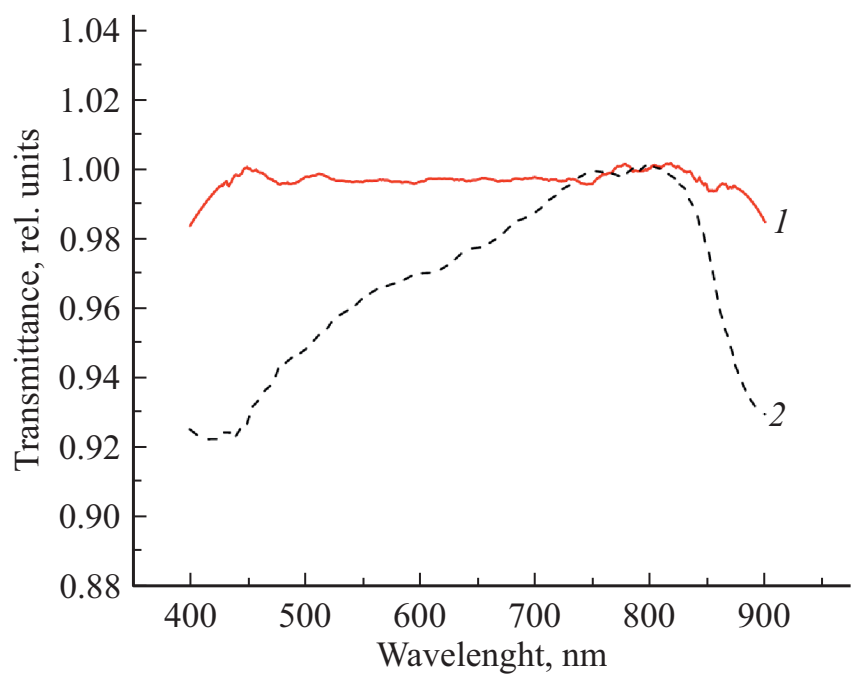

Рис. 3. Нормированные спектры пропускания немодифицированного силикатного стекла (1) и модифицированных областей, записанных в объеме стекла при линейной поляризации, перпендикулярной направлению записывающего пучка (2). 
$a$
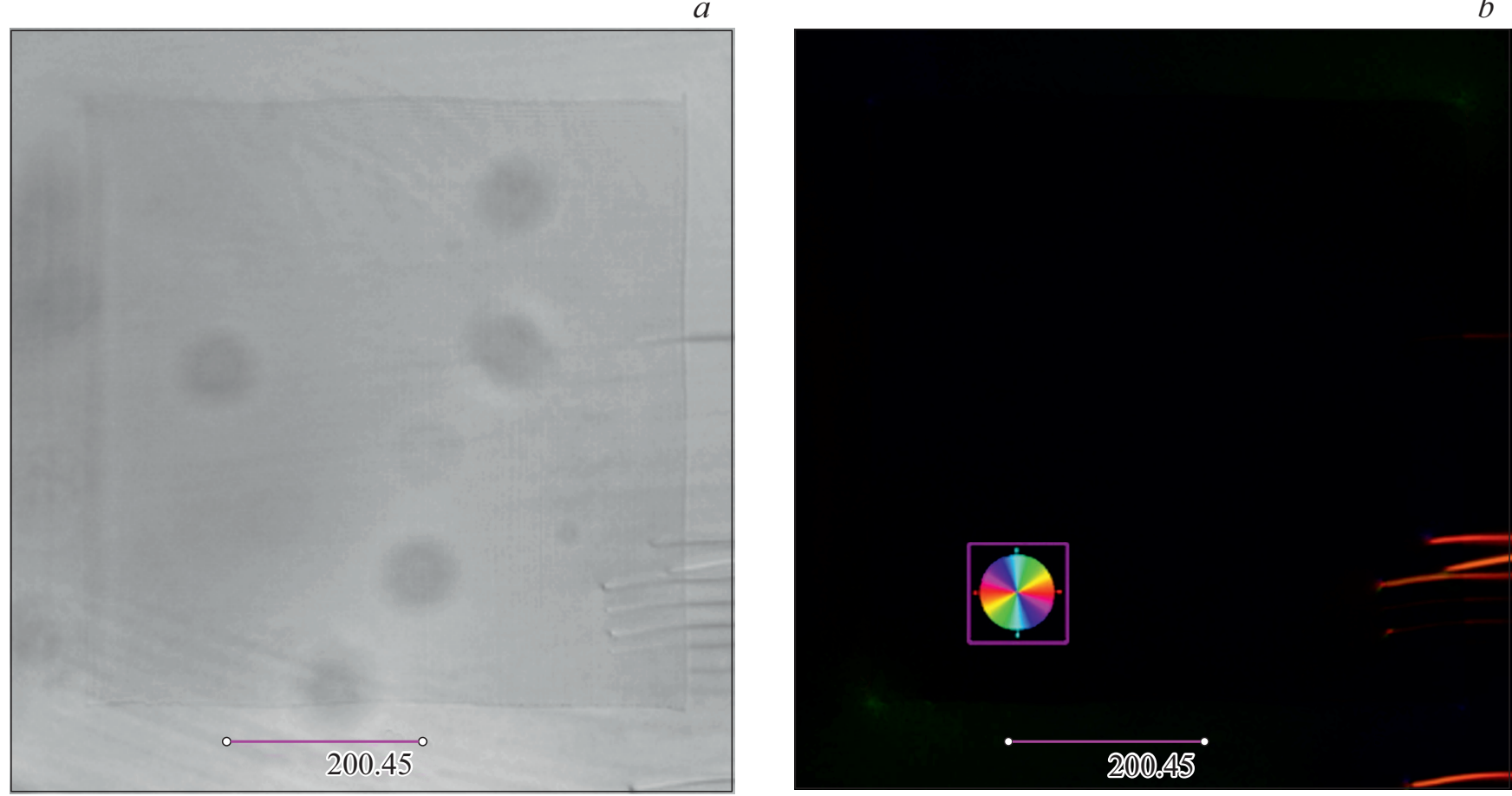

Рис. 4. Изображение модифицированной области, полученное посредством микроскопа Olympus BX-61, оснащенного системой анализа двулучепреломления Abrio. Объектив Olympus UPlanFIN 10x (NA =0.3): (a) фотография объекта и $(b)$ ориентационная псевдоцветовая карта, показывающая распределение величины фазового сдвига и направление медленной оси.

вдоль или перпендикулярно направлению сканирования. Изменение коэффициента пропускания в синей спектральной области можно связать как с генерацией центров окраски, так и усиленным рассеянием на неоднородностях объемной микроструктуры массивов. Влияние поляризации при записи массивов микролиний и в их спектрах пропускания проявляется в виде более слабых оптических эффектов для круговой поляризации. Можно предположить, что нелинейные эффекты фотоионизации силикатного стекла, несмотря на изотропность его оптических, электронных и структурных свойств, существенно зависят от амплитуды электрического поля ультракоротких лазерных импульсов в определенном направлении [7]. При этом изотропность материала проявляется в сходстве спектров микроструктур, записанных с линейной поляризацией в разных направлениях (рис. 3).

Анализ записанных структур с помощью системы микроанализа Abrio (рис. 4) показал, что данные структуры не являются двулучепреломляющими, т.е. ориентационная псевдоцветовая карта для записанного фемтосекундными импульсами квадрата не содержит цветных структур (рис. 4,b), соответствующих наведенной анизотропии. Модуляции в спектрах пропускания связаны с разницей показателей преломления в модифицированных и немодифицированной областях.

\section{Заключение}

В ходе настоящей работы с помощью ультракоротких лазерных импульсов при различных поляризациях в объеме силикатного стекла и одномерном линейном сканировании были записаны микроструктуры в виде массивов параллельных микролиний (при линейной поляризации) или перпендикулярно-параллельных микролиний (при круговой поляризации). Линейные структуры демонстрируют более высокую экстинкцию, усиленную в синей области спектра. Все полученные микроструктуры не обладают двулучепреломлением.

\section{Конфликт интересов}

Авторы заявляют, что у них нет конфликта интересов.

\section{Список литературы}

[1] Tan D., Sharafudeen K.N., Yue Y., Qiu J. // Prog. Mater. Sci. 2016. P. 154-228.

[2] Gattass R., Mazur E. // Nature Photon. 2008. P. 219-225. doi 10.1038/nphoton.2008.47

[3] Zhang J., Cerkauskaitê A., Drevinskas R., Patel A., Beresna M., Kazansky P.G. // Proc. SPIE. 2016. doi 10.1117/12.2220600

[4] Shimotsuma Y., Kazansky P.G., Qiu J., Hirao K. // Phys. Rev. Lett. 2003. V. 91.247405 
[5] Mills J.D., Kazansky P.G., Bricchi E., Baumberg J.J. // Appl. Phys. Lett. 2002. V. 81. P. 196-198.

[6] Fan H., Ryu M., Honda R., Morikawa J., Li Z.Z., Wang L., Maksimovic J., Juodkazis S., Chen Q.D., Sun H.B. // Nanomater. 2019. V. 9. P. 1414. doi 10.3390/nano9101414

[7] Temnov V.V., Sokolowski-Tinten K., Zhou P., El-Khamhawy A., von der Linde D. // Phys. Rev. Lett. 2006. V. 8. 237403. doi 10.1103/PhysRevLett.97.237403

[8] Beresna M., Gecevičius M., Kazansky P.G., Certus T. // Appl. Phys. Lett. 2011. V. 98. 201101. doi 10.1063/1.3590716

[9] Mehta S.B., Shribak M., Oldenbourg R. // J. Opt. 2013. V. 15. P. 094007. 